\title{
Biochemical status, oxidative and antioxidant responses after 3-month specific training in elite karate athletes
}

\author{
H Jemili ${ }^{1,2}$, MA Mejri ${ }^{2,3}$, E Bouhlel $^{2,4}$, M Amri ${ }^{1}$ \\ ${ }^{1}$ Research Unit of Functional Neurophysiology and Pathology, Biology Department, Faculty of Sciences Tunis, \\ University of Tunis El Manar, Tunis, Tunisia \\ ${ }^{2}$ High Institute of Sport and Physical Education, Ksar-Saïd, Manouba University, Tunis, Tunisia \\ ${ }^{3}$ Research Laboratory "Sport Performance Optimization", National Center of Medicine and Sciences in Sport \\ (CNMSS), Tunis, Tunisia \\ ${ }^{4}$ Research Unit, “Adaptations Cardio-circulatoires, Respiratoires, Métaboliques et Hormonales”, Faculty of Medicine \\ Ibn El Jazzar, University of Sousse, Sousse, Tunisia
}

Received: February 24, 2017

Accepted: November 13, 2017

\begin{abstract}
Aim: To investigate the effects of 3-month-long specific training program on biochemical status, oxidative and antioxidant responses in elite karatekas. Methods: Twenty male karatekas [BMI: $\left.21.9 \pm 2.4\left(\mathrm{~kg} / \mathrm{m}^{2}\right)\right]$ participated in this study. They performed a 3-month specific training to prepare for an international competition. We measured selected biochemical parameters, the oxidative and antioxidant responses before (T0) and after 3 months of intense karate training (T1). Results: We found significant increases in catalase activity $(26.3 \% \pm 21.3 \%, p<0.0005)$, superoxide dismutase activity $(15.9 \% \pm 28.8 \%, p<0.05)$, and a significant decrease in malondialdehyde levels $(17.2 \% \pm 13.7 \%, p<0.0005)$ after 3 months of karate training. Moreover, the athletes' biochemical status was significantly improved at T1 compared with T0 (for the majority of parameters, $p<0.0005$ ). Conclusions: The specific training program improves the prooxidant-antioxidant balance of elite karate athletes. It could be recommended for athletes having similar physical fitness level.
\end{abstract}

Keywords: oxidative stress, balance prooxidant-antioxidant, free radicals, muscular damage, inflammatory enzymes, athletes, martial arts, training

\section{Introduction}

Karate is a polystructural acyclic sport (36), characterized by an intermittent physical activity, engaging very intense punches and kicks $(9,43)$. Karate elite athletes are usually prescribed a mixed training regime that elicits adaptations in both anaerobic and aerobic energy pathways $(6,17,44)$. Indeed, karate training has been shown to increase muscular strength; functional mobility; mental, moral, and physical health; and self-actualization (8, 40). Moreover, recently, it has been found that intensive karate training induced higher muscle activation during the execution of karate-specific kicks (23). However, little is known about the adaptive responses of the biochemical status, oxidative and antioxidant systems after specific training among elite karatekas.

Corresponding author: Haifa Jemili

Research Unit of Functional Neurophysiology and Pathology, Biology Department, Faculty of Sciences Tunis, University of Tunis El Manar

2092 El Manar II, Tunis, Tunisia

Phone: +216 971219 48; Fax: +216 719046 14; E-mail: haifaje@yahoo.fr 
Some studies have shown that oxidative stress biomarkers increased following both aerobic and anaerobic exercises $(21,22,36,38)$. However, some reports showed some controversies, probably due to many various factors, such as the training volume and/or the athlete's physical fitness level $(19,41,42,47)$. Teixeira et al. (47) showed that a very large volume of training performed by elite athletes could lead to chronic oxidative stress state and to the alteration of physical performance. Elosua et al. (19) reported that a 6-week aerobic physical activity program remarkably increased the endogenous antioxidant activity and decreased the oxidative stress biomarkers among sedentary healthy young men and women.

In addition, there are relatively few studies, which have investigated the effect of training on the biochemical, oxidative stress, and antioxidant status in elite martial art athletes, preparing for an international competition $(12,16,33,34,36)$. In addition, the results are somewhat equivocal. For example, Naghizadeh et al. (33) found a significant improvement in the antioxidant status of karate athletes, in comparison with non-athletes, after a 6-month training program. However, Pesic et al. (36) reported a decrease in catalase (CAT) activity among male elite karate athletes after a 3-month training program.

Therefore, the aim of this study was to assess the effects of a 3-month karate-specific training program on biochemical parameters, oxidative stress and antioxidant status in male elite karatekas.

\section{Methods}

\section{Participants}

Twenty male karatekas $[18.2 \pm 2.1$ years, $175.9 \pm 5.9 \mathrm{~cm}, 67.8 \pm 9.5 \mathrm{~kg}$, BMI: $21.9 \pm 2.4$ $\left(\mathrm{kg} / \mathrm{m}^{2}\right), \%$ body fat: $11 \% \pm 1.6 \%$ ] from a Tunisian national team of Shotokan kumite volunteered to participate in this study. All athletes were non-smokers and healthy, and had no injury, no chronic, or acute diseases. They did not take any alimentary complements, medications, or supplements during the experiment. They were lodged in the national elite center and followed the same food regime.

They had $10.9 \pm 2$ years of experience. They trained $2 \mathrm{~h} /$ day $\times 9$ sessions/week. All participants were ranked as black belts (first Dan or greater). They were fully informed about the protocol procedures, including the possible risks and associated discomfort, and consequently signed an informed consent form before participating. For those under 18 years of age, the consent was obtained from their parents. The study was conducted in accordance with the Declaration of Helsinki, and the protocol fully approved by the local human research ethics committee before the commencement of the assessments.

The testing protocol comprised two sessions. The first session (T0) was realized at the beginning of the season (January), after a 1-month resting period. The second session (T1) was achieved after a 3-month karate-specific training program (to prepare the karatekas for an international competition "International Open of Nederland").

\section{Training program}

The specific training program was realized during a 3-month macrocycle (Table I). This program was divided into four periods. During the first period (i.e., cycle 1), the general objective was focused on the improvement of the aerobic capacity and the development of strength endurance $\left(60 \%-70 \%\right.$ of $\mathrm{VO}_{2 \max }$ or maximal strength). The exercises included 
Table I. Training program during 3-month macrocycle

\begin{tabular}{|c|c|c|c|c|c|}
\hline \multicolumn{6}{|c|}{ Structure of macrocycle } \\
\hline \multicolumn{3}{|c|}{ Cycle 1} & Cycle 2 & Cycle 3 & Cycle 4 \\
\hline \multicolumn{3}{|c|}{3 weeks } & 4 weeks & 3 weeks & 2 weeks \\
\hline W1 & W2 & W3 & \multirow{5}{*}{$\begin{array}{l}\text { Specific karate training } \\
\text { repetitive series of short } \\
\text { and intense exercises: } \\
\text { Power, speed, agility, } \\
\text { and coordination } \\
\text { circuit }(2 \times 20 \mathrm{~min} \text {; } \\
10 \text { min rest between) } \\
\text { Specific agility and } \\
\text { coordination circuit } \\
\text { (technique and } \\
\text { specific karate drills) } \\
(2 \times 20 \text { min; } 10 \text { min } \\
\text { rest between) }\end{array}$} & \multirow{5}{*}{$\begin{array}{l}\text { Karate-specific } \\
\text { interval training: } \\
\text { (Technique and } \\
\text { specific karate } \\
\text { drills) }(2 \times 30 \mathrm{~min} \text {; } \\
15 \text { min rest } \\
\text { between) } \\
\text { Specific karate } \\
\text { stretching ( } 30 \mathrm{~min}) \\
\text { Fight arbitrated } \\
\text { (randori) (Friday) } \\
\text { (90 min) }\end{array}$} & \multirow{5}{*}{$\begin{array}{l}\text { Tactical } \\
\text { situations } \\
\text { (90 min) } \\
\text { Sharpening } \\
\text { (last week) }\end{array}$} \\
\hline Aerobic capac & & & & & \\
\hline $\begin{array}{c}60 \% \mathrm{VO}_{2 \max } \\
\quad(40 \mathrm{~min})\end{array}$ & $\begin{array}{c}70 \% \mathrm{VO}_{2 \max } \\
(50 \mathrm{~min})\end{array}$ & $\begin{array}{c}70 \% \mathrm{VO}_{2 \max } \\
(60 \mathrm{~min})\end{array}$ & & & \\
\hline \multicolumn{3}{|l|}{ Strength } & & & \\
\hline $\begin{array}{l}50-60 \\
(\% \text { of } 1 \mathrm{RM}) \\
(60 \mathrm{~min})\end{array}$ & $\begin{array}{c}60-80 \\
(\% \text { of } 1 \mathrm{RM}) \\
(50 \mathrm{~min})\end{array}$ & $\begin{array}{c}80-100 \\
(\% \text { of } 1 \mathrm{RM}) \\
(40 \mathrm{~min})\end{array}$ & & & \\
\hline
\end{tabular}

total and segmental movements of upper limbs, trunk, and lower limbs. The second period (i.e., cycle 2) was dedicated to the development of power, speed, agility, and coordination circuits. The training was completed by two specific strength training sessions. The latter was developed using essential exercises, such as squat and overhead split squat with or without external loads, box crossover and box jump, push-ups, draw chest, bench and inclined bench presses, abdominals, and a variety of plyometric exercises for developing force-velocity of both lower and upper limbs. Cycle 3 was focused on a specific intense karate training, which mainly consisted of repetitive series of short and intensive exercises involving various components within a karate session specific interval training, technique and/or specific drills, such a guiaku-zuki and kiza-mawashi-guiri situation, and randori (freestyle sparring) each Friday. The last cycle was based on tactical schema situations (i.e., first week) and sharpening session (i.e., second week).

\section{Measurements and Protocols}

\section{Biochemical assays}

Blood samples from each participant were collected at rest before training (T0) and after the specific training program (T1) to verify the chronic effect of training. Samples were collected between 07:00 and 08:00 $\mathrm{h}$ (after a 12-h overnight fast). T1 samples were undertaken for $72 \mathrm{~h}$ following the last training session to avoid fatigue effects on metabolic parameters. Venous blood samples were collected by the same technician from the antecubital site in tubes (Vacutainer, Becton Dickinson, Franklin Lakes, NJ, USA) after $5 \mathrm{~min}$ of being in a seated position. All specimens were put in a cooler and quickly transported to the laboratory in a crushed ice block. Samples were centrifuged immediately at $3500 \times g$ and $4{ }^{\circ} \mathrm{C}$ for $12 \mathrm{~min}$. Aliquots of the resulting plasma were stored at $-80{ }^{\circ} \mathrm{C}$ for analyses. To eliminate interassay variance, all samples were analyzed in the same assay run. All biochemical parameters were 
performed in duplicates in the same laboratory using an automated analyzer (Beckman Coulter UniCel ${ }^{\circledR}$ DxC 600 Synchron $^{\circledR}$, Beckman Instruments, "Beckman Danville, California, USA"), with reagents, standards, and controls from Randox Laboratories (Crumlin, Northern Ireland, UK). The intraassay coefficients of variation for these parameters were $<7 \%$.

\section{Oxidative and antioxidant enzymes}

Plasma lipid peroxidation was estimated by measuring malondialdehyde (MDA) levels according to the double heating method (18). Aliquots $(250 \mu \mathrm{l})$ from the sample were mixed with $250 \mu \mathrm{l}$ butylated hydroxytoluene (BHT)-trichloroacetic acid (TCA) solution containing $1 \%$ BHT $(\mathrm{m} / \mathrm{v})$ dissolved in $20 \%$ TCA $(\mathrm{m} / \mathrm{v})$ and centrifuged at $1,000 \times g$ for 5 min at $4{ }^{\circ} \mathrm{C}$. The supernatant $(400 \mu \mathrm{l})$ was blended with $0.5 \mathrm{~N} \mathrm{HCl}(80 \mu \mathrm{l})$ and $120 \mathrm{mM}$ thiobarbituric acid (TBA) in $26 \mathrm{mM}$ Tris $(320 \mu \mathrm{l})$, and then heated at $80{ }^{\circ} \mathrm{C}$ for $10 \mathrm{~min}$. After cooling, the absorbance of the resulting pink chromophore was determined at $532 \mathrm{~nm}$ using a SmartSpec 3000 Bio-Rad UV-visible spectrophotometer (Germany). MDA levels were determined using an extinction coefficient for MDA-TBA complex of $1.56105 \mathrm{M}^{-1} \mathrm{~cm}^{-1}$. MDA concentration $(\mathrm{M})=$ absorbance at $532 \mathrm{~nm} / 1.56 \times 105$.

Superoxide dismutase (SOD) activity was determined by the epinephrine method (30), which is based on the capacity of the SOD to inhibit the autooxidization of the epinephrine in adrenochrome while trapping the flux of anion superoxide. The sample was mixed in a buffer of $\mathrm{Na}_{2} \mathrm{CO}_{3} / \mathrm{NaHCO}_{3}(50 \mathrm{mM}, \mathrm{pH}=10.2)$ with $10 \mu \mathrm{l}$ of bovine CAT $(0.4 \mathrm{U} / \mathrm{ml})$ and $20 \mu \mathrm{l}$ of epinephrine $(5 \mathrm{mg} / \mathrm{ml})$. The SOD activity in the samples was assessed by spectrophotometry. Detection was performed at $480 \mathrm{~nm}$ with a Bio-Rad spectrophotometer (Bio-Rad Laboratories, Philadelphia, USA).

The CAT is a metalloenzyme that transforms the peroxide of hydrogen in water and molecular oxygen according to the following reaction (1):

$$
2 \mathrm{H}_{2} \mathrm{O}_{2} \rightarrow 2 \mathrm{H}_{2} \mathrm{O}+\mathrm{O}_{2}
$$

The sample was mixed with phosphate buffer $(50 \mathrm{mM}, \mathrm{pH}=7)$. The kinetics of the CAT activity was spectrophotometrically measured at $240 \mathrm{~nm}$ in $3 \mathrm{~min}$ while measuring the decomposition of the $\mathrm{H}_{2} \mathrm{O}_{2}$. The $\mathrm{C}$ concentration of the CAT activity was calculated according to the law of Beer-Lambert.

\section{Statistical analysis}

All statistical tests were processed using the Statistical software SPSS version 20 for Windows (SPSS Inc., Chicago, IL, USA). All values are reported as mean and standard deviation (mean $\pm \mathrm{SD}$ ). The Shapiro-Wilk W test revealed that the data were normally distributed. Once the assumption of normality was confirmed, data were analyzed using the parametric test (Student's $t$-test for matched samples) for the intragroups comparison of parameters. Data obtained at the beginning of the season (T0) were compared with those obtained after the 3-month training period (T1). Cohen's $d$ effect sizes (ES) were calculated to assess the practical significance of the findings. ES was interpreted as: $d<0.20$ (trivial), $d=0.20-0.49$ (small), $d=0.50-0.79$ (medium), and $d \geq 0.80$ (large) (11). The precision of point estimates is quantified through $95 \%$ confidence intervals (CI). The level of significance 
was set at $p<0.05$. When the SPSS output demonstrated significance levels less than 0.001 , these were corrected to $p<0.0005$ (25).

\section{Results}

A general linear model showed significant differences between the beginning of the season (T0) and after 3 months of karate training (T1) with respect to biochemical status (Table II). All values were obtained before and after training, corresponding to the margin of the usual values.

We found significant increases in CAT [ $(p<0.0005$; with amplitude of $26.3 \% \pm 21.3 \%$; with mean differences of $4.16 ; 95 \% \mathrm{CI}=-5.51$ to -2.81 ; $\mathrm{ES}=1.305$ ) (Fig. 1)] and SOD $[(p<0.05$; with amplitude of $15.9 \% \pm 28.8 \%$; with mean differences of 0.06 ; $95 \%$ $\mathrm{CI}=-0.11$ to -0.01 ; $\mathrm{ES}=0.189$ ) (Fig. 2)] values after a 3 -month training.

We also found a significant decrease in MDA values $[(p<0.0005$; with amplitude of $17.2 \% \pm 13.7 \%$; with mean differences of $0.06 ; 95 \% \mathrm{CI}=0.04-0.09 ; \mathrm{ES}=0.92$ ) (Fig. 3) $]$ after training.

\section{Discussion}

The major finding of this study is the improvement of the antioxidant status (i.e., CAT and SOD activities) and the decrease of the biochemical parameters and MDA levels after a 3-month intensive karate training program.

In agreement with the literature, we found increases in CAT and SOD activities (19, 32, $33,36)$. SOD activity is significantly higher in athletes than non-athletes $(20,28)$. Dopsaj et al. (16) reported higher SOD activity in wrestlers compared with karate professionals, during the precompetitive period. In a recent study, Koubaa et al. (26) have reported that a 12-week training period increases the SOD activity among sedentary male smokers. Zivkovic et al. (49) found the same tendency in young soccer players after a 6-month training program. Pesic et al. (36) found increases in SOD activity after a training period of 3 months, without reaching the level of statistical significance.

Regarding CAT activity, our findings are in agreement with recent studies $(15,48,49)$. Tong et al. (48) showed a marked increase in serum CAT activity in runners after a 12-week training period. In addition, Zivkovic et al. (49) found increases in CAT activity in young soccer players after a 6-month training program. Moreover, CAT activity is higher in young handball players compared with non-athletes (15).

However, Pesics et al. (36) reported a decrease in CAT activity after a 3-month karate training program. The authors suggest that this result might indicate that athletes need antioxidant supplementation (35). Other studies reported unchanged CAT activity after training $(4,24,32)$. The rise of CAT activity observed in our investigation may indicate that, during the training period, the antioxidant system has more time to adapt to oxidative stress (48). Indeed, the increase in the activities of these enzymes (i.e., SOD and CAT) was probably counteracting the generation of oxygen-derived free radicals promoted by karate session (38). On the other hand, in this study, the significant increase in antioxidant markers activity was produced by predominate aerobic training during endurance and tactical situations (cycles 1 and 4) (19), and predominated anaerobic training during cycles 2 and 3 $(41,42)$. In this context, it has been demonstrated that regular exercise training, when compounded by "explosive," "high intensity," or "endurance intensive" efforts (10), appears 


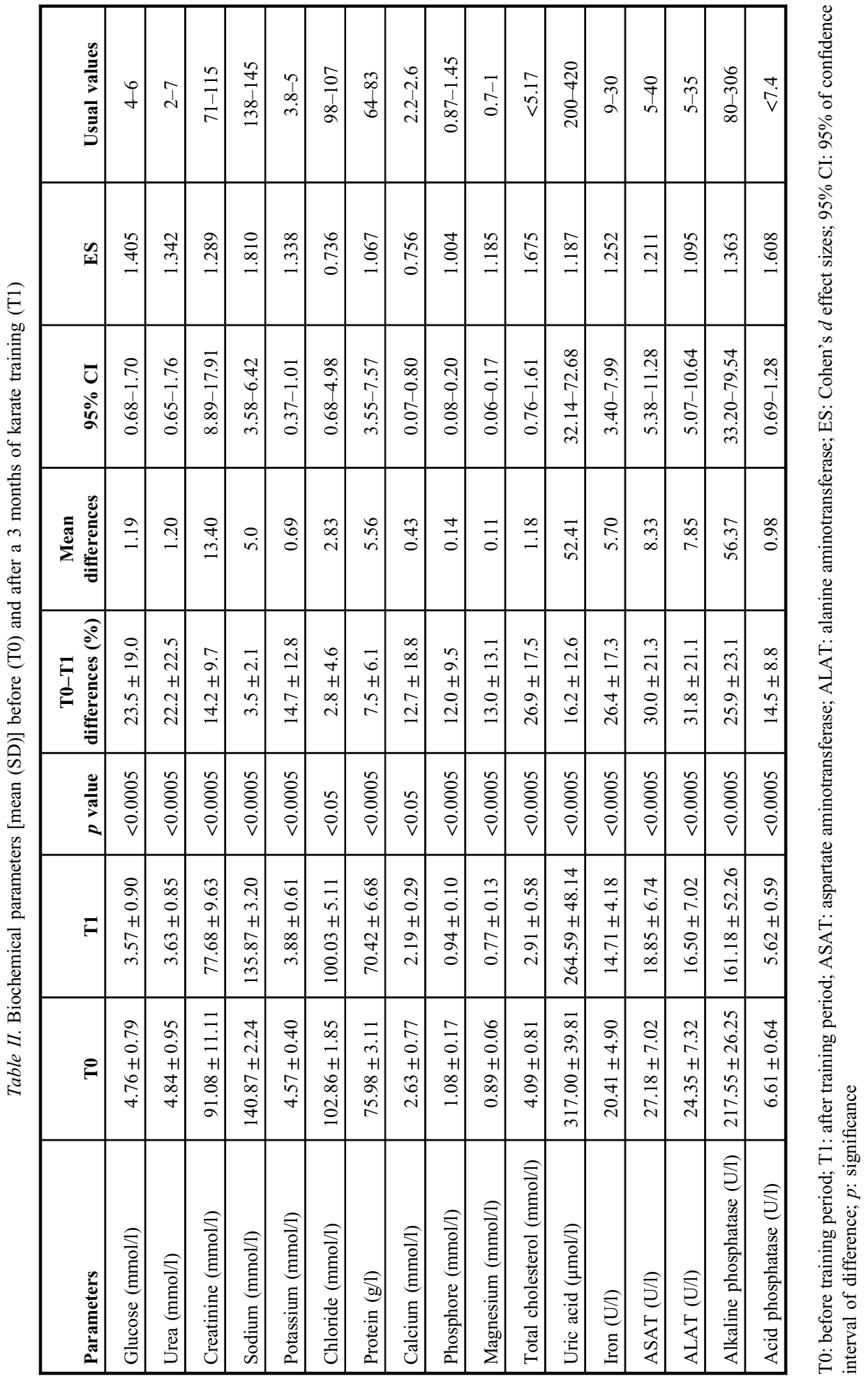



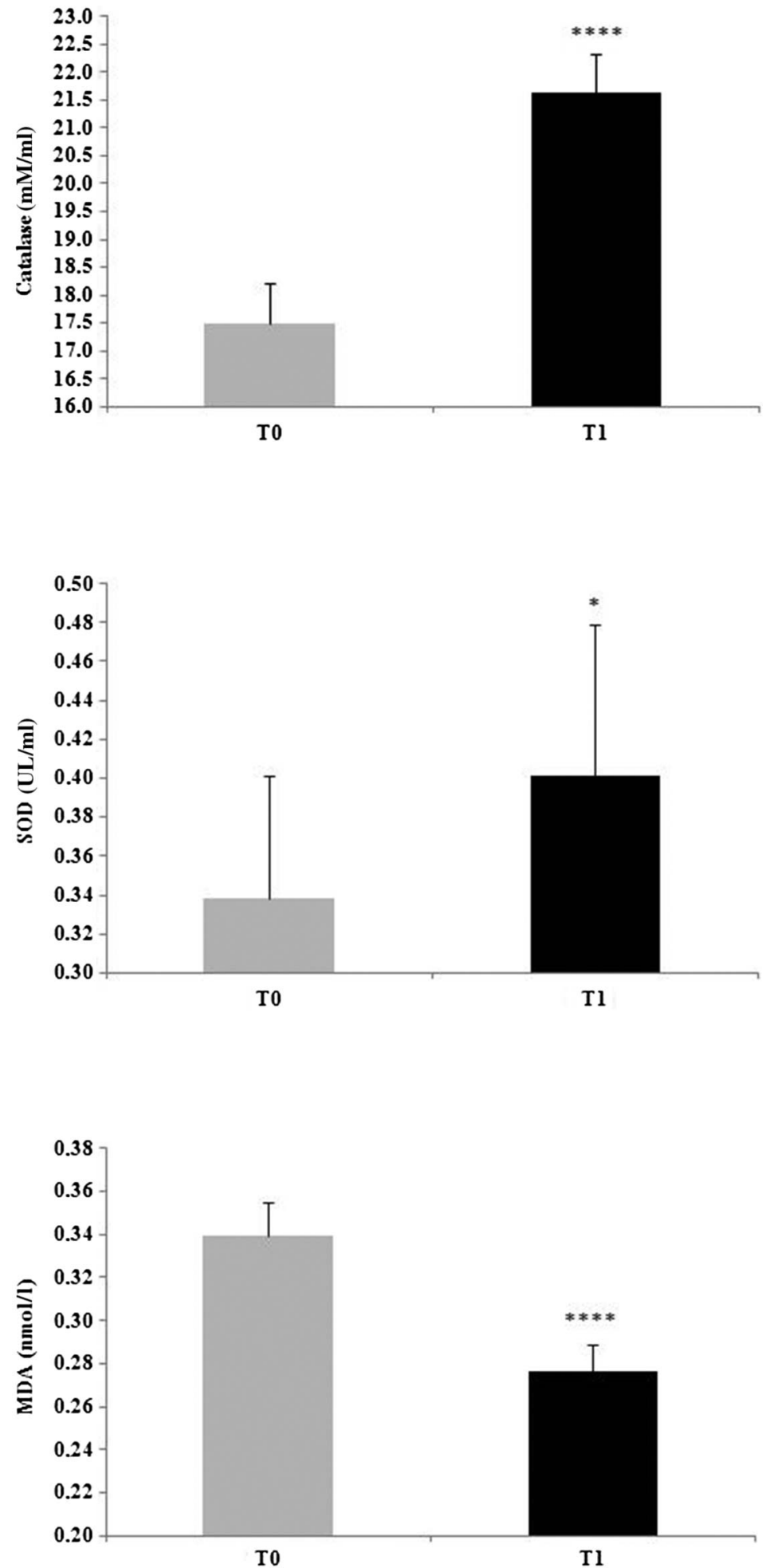

Fig. 1. Basal CAT activity (mean \pm SEM) of elite karatekas before (T0) and after (T1) the 3-month karate training program. CAT: catalase. $* * * *$ Significant difference between T0 and T1 $(p<0.0005)$

Fig. 2. Basal SOD activity (mean \pm SEM) of elite karatekas before (T0) and after (T1) the 3-month karate training program. SOD: superoxide dismutase. *Significant difference between T0 and T1 $(p<0.05)$
Fig. 3. Basal MDA levels (mean \pm SEM) of elite karatekas before (T0) and after (T1) the

3-month karate training program. MDA: malondialdehyde levels. **** Significant difference between T0 and T1 $(p<0.0005)$ 
to improve antioxidant defense mechanisms, providing additional protection during times of acute physical stress (39). Accordingly, antioxidant status improvements may suggest positive effects of the specific training program in elite karatekas.

This study also showed that the basal MDA levels of our athletes significantly decreased after the training period. These findings are in agreement with previous observations among other populations (i.e., namely on sedentary male smokers) after a 12-week training program (26), as well as in cyclists who spent 13 days at an altitude of 2,500-3,000 m, and trained at $1,200 \mathrm{~m}$ above sea level (37), and also for soccer players who have realized regular training (29). In the same line, Miyazaki et al. (32) found that 12-week endurance intensive training program decreased the basal lipid peroxidation and improved the antioxidant status [i.e., SOD and glutathione peroxidase (GPX) activities] compared with the pretraining among untrained male subjects. According to the authors, the improvement of the antioxidant defense system would result from a reduction of acute aerobic exercise-induced lipid peroxidation, increases in the athletes' resistance and chronic adaptation to subsequent oxidative stress. Elosua et al. (19) reported an increase in antioxidant enzyme activity [i.e., blood GPX, plasmatic glutathione reductase, and low-density lipoprotein (LDL) resistance to oxidation] and a decrease in oxidative stress markers levels (i.e., oxidized LDL) after 16 weeks of aerobic training, among sedentary healthy young volunteers. Given these improvements, the authors suggested that the antioxidant activity increase may result from endogenous antioxidant production related to the repeated increases of free radicals acting as inductors of gene transcription after each aerobic training session (46).

In this study, the improvement of antioxidant status and the decrease of oxidative stress markers suggest that anaerobic exercises (i.e., "explosive" and "high intensity" efforts) used during the karate-specific training program can increase oxidation of macromolecules, potentially leading to tissue damage (7), whereas chronic training can induce adaptations that attenuate the exercise-induced oxidative stress (7). In this context, Radak et al. (41) reported that the stimulatory effect of anaerobic exercise on reactive oxygen and nitrogen species (RONS) generation appears to be an important phenomenon of the exercise-induced adaptation process. Thereby, the increased antioxidant enzyme activity in response to training is apparently due to the system's need to generate antioxidants to facilitate protection against RONS. Bloomer and Goldfarb (7) affirmed that the decrease in RONS markers may also be due to repeated and prolonged exposure to high RONS generation, resulting in alterations in the production of these RONS. According to these authors (42), such adaptation exists to attenuate the typical rise in protein, lipid, DNA, and glutathione oxidation following a single bout of exercise, which appears to be valuable for both aerobic and anaerobic exercises. In view of the above considerations, the present results could also suggest that the training load used in this program was efficient to induce improvement in antioxidant status and the decrease of oxidative stress biomarker levels among karate athletes (16). Furthermore, other factors could be related to these findings, such as physical fitness level and/or training experience (16) of our elite karate athletes.

Concerning the markers of renal (i.e., creatinine, protein, uric acid, urea, sodium, potassium, calcium, phosphor, and chloride), hepatic [i.e., alanine aminotransferase (ALAT), aspartate aminotransferase (ASAT), alkaline phosphatase, and acid phosphatase], and metabolic functions (i.e., glucose, magnesium, iron, and total cholesterol), we found a significant decrease in these parameters after training, without reaching clinical significances. In the same manner, Miura et al. (31) found no significant changes in hepatic enzymes levels, such as ASAT and ALAT, after a 6-month training program among judo athletes. However, 
other studies found that these hepatic function markers can significantly increase following a single intensive training session or an acute physical exercise $(2,3,5,13,27,31)$. Similarly, we observed a significant decrease of the urea and uric acid plasma levels after the training program. These changes may be an indication of decreased protein catabolism (14).

Our blood analyses are of interest. First, they gave an initial appreciation of the renal, hepatic, and metabolic functions of our athletes; second, they permit to assess training adaptations, and/or status of undertraining, or overtraining syndrome following 3 months of intensive karate training (45).

The present findings include some limitations. It would be interesting to measure the responses of the hormonal, cytokine, and biomarkers of muscular damage (e.g., creatine kinase, myoglobin, lactate dehydrogenase, and C-reactive protein) before and following the karate intensive training program to establish the relationships between biomarkers of fatigue and the immune system. The lack of a control group is another limitation of this study. In fact, the comparison of the results with those of a control group (i.e., sedentary subjects) could well highlight the effect of the karate-specific training program on biochemical, oxidative, and antioxidant statuses, among karate elite athletes. However, in practice, it is difficult to find a control group composed of elite athletes who accept not to train for such a long period. In addition, dietary intakes of our athletes may influence our data. Nevertheless, our athletes follow the same dietary intakes, because they live and train in a training national center. Dietary intakes should influence the selected parameters in the same manner. In conclusion, the intensive-specific training program significantly improved the prooxidant-antioxidant status balance among karate elite athletes. The increase in SOD and CAT values, associated with the reduction of the biochemical responses and MDA activity, highlights the effectiveness of this training program among karate elite athletes. Our data give additional information about the evolution of the prooxidant-antioxidant status in elite athletes preparing for a serious competition. Furthermore, these findings could inspire coaches to prepare adapted training for karate athletes.

\section{Acknowledgements}

The authors would like to express their sincere gratitude to all the participants for their maximal effort and cooperation. They alone are responsible for the content and writing of the paper.

\section{Conflict of interest}

The authors report no conflict of interest.

\section{REFERENCES}

1. Aebi H: Catalase in vitro. Methods Enzymol. 105, 121-126 (1984)

2. Andreato LV, Franzói de Moraes SM, Esteves JVDC, Pereira RRA, Gomes TLM, Andreato TV, Franchini E: Physiological responses and rate of perceived exertion in Brazilian jiu-jitsu athletes. Kinesiology (Zagreb) 44, 173-181 (2012)

3. Andreato LV, Julio UF, Panissa VL, Esteves JV, Hardt F, de Moraes SM, de Souza CO, Franchini E: Brazilian jiu-jitsu simulated competition part I: Metabolic, hormonal, cellular damage, and heart rate responses. J. Strength Cond. Res. 29(9), 2538-2549 (2015)

4. Balakrishnan SD, Anuradha CV: Exercise, depletion of antioxidants and antioxidant manipulation. Cell Biochem. Funct. 16, 269-275 (1998)

5. Barbas I, Fatouros IG, Douroudos II, Chatzinikolaou A, Michailidis Y, Draganidis D, Jamurtas AZ, Nikolaidis MG, Parotsidis C, Theodorou AA, Katrabasas I, Margonis K, Papassotiriou I, Taxildaris K: Physiological and 
performance adaptations of elite Greco-Roman wrestlers during a one-day tournament. Eur. J. Appl. Physiol. 111, 1421-1436 (2011)

6. Beneke R, Beyer T, Jachner C, Erasmus J, Hutler M: Energetics of karate kumite. Eur. J. Appl. Physiol. 92, 518-523 (2004)

7. Bloomer RJ, Goldfarb AH: Anaerobic exercise and oxidative stress: A review. Can. J. Appl. Physiol. 29(3), 245-263 (2004)

8. Bu B, Haijun H, Yong L, Chaohui Z, Xiaoyuan Y, Singh MF: Effects of martial arts on health status: A systematic review. J. Evid. Based Med. 3(4), 205-219 (2010)

9. Chaabane H, Mkaouer B, Franchini E, Souissi N, Selmi MA, Nagra Y, Chamari K: Physiological responses and performance analysis difference between official and simulated karate combat conditions. Asian J. Sports Med. 5(1), 21-29 (2014)

10. Chamari K, Padulo J: 'Aerobic' and 'Anaerobic' terms used in exercise physiology: A critical terminology reflection. Sports Med. Open 1, 9 (2015)

11. Cohen J (1988): Statistical power analysis for the behavioral science (2nd ed.). Lawrence Erlbaum Associates, Hillsdale, NJ

12. Cordeiro EM, Gomes ALM, Guimarães M, da Silva SG, Dantas EHM: Hematological and biochemical alterations originating from the combat training in of Olympic kung fu athletes. Fitness Perform. J. 6, 255-261 (2007)

13. Coswig VS, Neves AHS, Del Vecchio FB: Biochemical, hormonal and hematological responses to Brazilian jiu-jitsu matches. J. Braz. Sci. Mov. 21, 19-30 (2013)

14. Degoutte F, Jouanel P, Filaire E: Energy demands during a judo match and recovery. Br. J. Sports Med. 37 , 245-249 (2003)

15. Djordjevic D, Cubrilo D, Macura M, Barudzic N, Djuric D, Jakovljevic V: The influence of training status on oxidative stress in young male handball players. Mol. Cell. Biochem. 351, 251-259 (2011)

16. Dopsaj V, Martinovic J, Dopsaj M, Kasum G, Kotur-Stevuljevic J, Koropanovski N: Hematological, oxidative stress, and immune status profiling in elite combat sport athletes. J. Strength Cond. Res. 27, 3506-3514 (2013)

17. Doria C, Veicsteinas A, Limonta E, Maggioni MA, Aschieri P, Eusebi F, Fano G, Pietrangelo T: Energetics of karate (kata and kumite techniques) in top-level athletes. Eur. J. Appl. Physiol. 107, 603-610 (2009)

18. Draper HH, Hadley M: Malondialdehyde determination as index of lipid peroxidation. Methods Enzymol. 186, 421-431 (1990)

19. Elosua R, Molina L, Fito M, Arquer A, Sanchez-Quesada JL, Covas MI, Ordoñez-Llanosc J, Marrugat J: Response of oxidative stress biomarkers to a 16-week aerobic physical activity program, and to acute physical activity, in healthy young men and women. Atherosclerosis 167, 327-334 (2003)

20. Gomez-Cabrera MC, Domenech E, Vina J: Moderate exercise is an antioxidant: Upregulation of antioxidant genes by training. Free Radic. Biol. Med. 44, 126-131 (2008)

21. Hammouda O, Chtourou H, Aloui A, Mejri MA, Chahed H, Miled A, Chamari K, Chaouachi A, Souissi N: Does Ramadan fasting affect the diurnal variations in metabolic responses and total antioxidant capacity during exercise in young soccer players? Sport Sci. Health 10(2), 97-104 (2014)

22. Hammouda O, Chtourou H, Chahed H, Ferchichi S, Kallel C, Miled A, Chamari K, Souissi N: Diurnal variation of plasma homocysteine, total antioxidant status and biological markers of muscle injury during repeated sprint: Effects on performance and muscle fatigue - A pilot study. Chronobiol. Int. 28, 958-967 (2011)

23. Jemili H, Mejri MA, Sioud R, Bouhlel E, Amri M: Changes in muscle activity during karate guiaku-zuki-punch and kiza-mawashi-guiri-kick after specific training in elite athletes. Sci. Sports 32(2), 73-81 (2017)

24. Ji LL: Exercise-induced modulation of antioxidant defense. Ann. N. Y. Acad. Sci. 959, 82-92 (2002)

25. Kinnear PR, Gray CD (1995): SPSS for Windows made simple. Lawrence Erlbaum Associates, Hove

26. Koubaa A, Triki M, Trabelsi H, Baati H, Sahnoun Z, Hakim A: The effect of a 12-week moderate intensity interval training program on the antioxidant defense capability and lipid profile in men smoking cigarettes or hookah: A cohort study. Sci. World J. 2015, 639369 (2015)

27. Kraemer WJ, Fry AC, Rubin MR, Triplett-Mcbride T, Gordon SE, Perry KL, Lynch JM, Volek JS, Meuffels DE, Newton RU, Fleck SJ: Physiological and performance responses to tournament wrestling. Med. Sci. Sports Exerc. 33, 1367-1378 (2001)

28. Martinovic J, Dopsaj V, Dopsaj M, Kotur-Stevuljevic J, Vujovic A, Stefanovic A, Nesic G: Long-term effects of oxidative stress in volleyball players. Int. J. Sports Med. 30, 851-856 (2009)

29. Metin G, Gumustas MK, Uslu E, Belce A, Kayserilioglu A: Effect of regular training on plasma thiols, malondialdehyde and carnitine concentrations in young soccer players. Chin. J. Physiol. 46, 35-39 (2003) 
30. Misra HP, Fridovich I: The role of superoxide anion in the autoxidation of epinephrine and a simple assay for superoxide dismutase. J. Biol. Chem. 247, 3170-3175 (1972)

31. Miura M, Umeda T, Nakaji S, Liu Q, Tanabe M, Kojima A, Sugawara K: Effect of 6 months' training on the reactive oxygen species production capacity of neutrophils and serum opsonic activity in judoists. Luminescence 20(1), 1-7 (2005)

32. Miyazaki H, Oh-ishi S, Ookawara T, Kiyaki T, Toshinai K, Ha S, Haga S, Ji LL, Ohno H: Strenuous endurance training in humans reduces oxidative stress following exhausting exercise. Eur. J. Appl. Physiol. 84, 1-6 (2001)

33. Naghizadeh H, Afzalpour ME, Zarban A: The comparison of antioxidant status and lipid profile of karate athletes with non athletes. J. Birjand Univ. Med. Sci. 16(3), 54-61 (2009)

34. Palasuwan A, Suksom D, Margaritis I, Soogarun S, Rousseau AS: Effects of tai chi training on antioxidant capacity in pre- and postmenopausal women. J. Aging Res. 2011, 234696 (2011)

35. Pesić S, Jakovljević V, Cubrilo D, Zivković V, Jorga V, Mujović V, Stojimirović B: Oxidative status evaluation in elite karate athletes during training process. Vojnosanit. Pregl. 66, 551-555 (2009)

36. Pesic S, Jakovljevic V, Djordjevic D, Cubrilo D, Zivkovic V, Jorga V, Stojimirovic B: Exercise-induced changes in redox status of elite karate athletes. Chin. J. Physiol. 55, 8-15 (2012)

37. Pialoux V, Mounier R, Ponsot E, Rock E, Mazur A, Dufour S, Richard R, Richalet JP, Coudert J, Fellmann N: Effects of exercise and training in hypoxia on antioxidant/pro-oxidant balance. Eur. J. Clin. Nutr. 60, 1345-1354 (2006)

38. Poprzęcki S, Czuba M, Zając A, Karpiński J, Wilk R, Bril G, Maszczyk A, Toborek M: The blood antioxidant defence capacity during intermittent hypoxic training in elite swimmers. Biol. Sport 33, 353-360 (2016)

39. Powers SK, Ji LL, Leeuwenburgh C: Exercise training-induced alterations in skeletal muscle antioxidant capacity: A brief review. Med. Sci. Sports Exerc. 31, 987-997 (1999)

40. Quinzi F, Camomilla V, Felici F, Di Mario A, Sbriccoli P: Agonist and antagonist muscle activation in elite athletes: Influence of age. Eur. J. Appl. Physiol. 115(1), 47-56 (2015)

41. Radak Z, Sasvari M, Nyakas C, Pucsok J, Nakamotot H, Goto S: Exercise preconditioning against hydrogen peroxide-induced oxidative damage in proteins of rat myocardium. Arch. Biochem. Biophys. 376, 248-251 (2000)

42. Radak Z, Taylor AW, Ohno H, Goto S: Adaptation to exercise-induced oxidative stress: From muscle to brain. Exerc. Immun. Rev. 7, 90-107 (2001)

43. Ravier G, Dugue B, Grappe F, Rouillon JD: Impressive anaerobic adaptations in elite karate athletes due to few intensive intermittent sessions added to regular karate training. Scand. J. Med. Sci. Sports 19, 687-694 (2009)

44. Ravier G, Dugue B, Grappe F, Rouillon JD: Maximal accumulated oxygen deficit and blood responses of ammonia, lactate, and $\mathrm{pH}$ after anaerobic test: A comparison between international and national elite karate athletes. Int. J. Sports Med. 27, 810-817 (2006)

45. Rowbottom DG, Keast D, Garcia-Webb P, Morton AR: Training adaptation and biological changes among well-trained male triathletes. Med. Sci. Sports Exerc. 29, 1233-1239 (1997)

46. Sen CK, Packer L: Antioxidant and redox regulation of gene transcription. FASEB. J. 10, 709-720 (1996)

47. Teixeira V, Valente H, Casal S, Pereira L, Marques F, Moreira P: Antioxidant status, oxidative stress, and damage in elite kayakers after 1 year of training and competition in 2 seasons. Appl. Physiol. Nutr. Metab. 34, 716-724 (2009)

48. Tong TK, Kong Z, Lin H, He Y, Lippi G, Shi Q, Zhang H, Nie J: Effects of 12-week endurance training at natural low altitude on the blood redox homeostasis of professional adolescent athletes: A quasi-experimental field trial. Oxid. Med. Cell. Longev. 2016, 4848015 (2016)

49. Zivkovic V, Lazarevic P, Djuric D, Cubrilo D, Macura M, Vuletic M, Barudzic N, Nesic M, Jakovljevic V: Alteration in basal redox state of young male soccer players after a six-month training programme. Acta Physiol. Hung. 100(1), 64-76 (2013) 